\title{
Perfil de la migración interna en Costa Rica pre y post aprobación Tratado de Libre Comercio entre Estados Unidos, Centroamérica y República Dominicana
}

Recibido: 23 de abril 2018

Revisado: 4 de julio 2018

Aprobado: 8 de agosto 2018

\section{Laura Solís Bastos}

Costarricense. Socióloga,

Máster en Estudios

Latinoamericanos con

énfasis en Cultura y

Desarrollo, por el Instituto

de Estudios

Latinoamericanos,

Universidad Nacional de

Costa Rica. Investigadora

del Instituto de Estudios

Sociales en Población

(IDESPO) de la Universidad

Nacional de Costa Rica.

Actualmente labora temáticas relacionadas con la política costarricense, las migraciones, la identidad y

la calidad de vida.

Correo electrónico:

laura.solis.bastos@una.cr

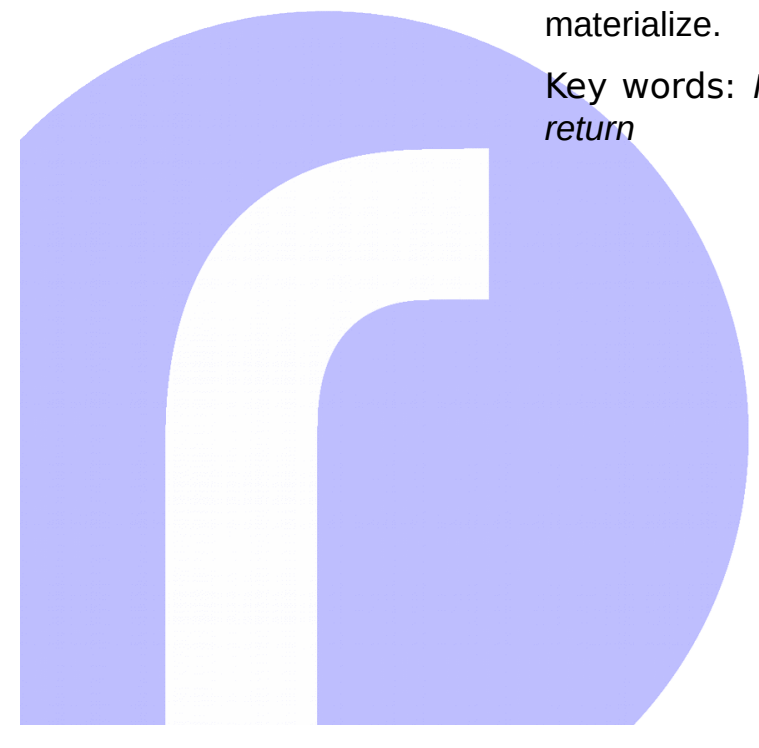
materialize. return
Resumen: Este artículo se enfoca en el análisis de los datos censales de las rondas de 2000 y 2011 para la caracterización del perfil de la migración interna antes y después de la aprobación en Costa Rica del TLC. Los resultados muestran que tanto en flujos migratorios, como en las etapas migratorias no se encontraron diferencias significativas en los resultados obtenidos. Históricamente en el estudio de las migraciones, el empleo es uno de los principales motivos para la movilidad poblacional; asimismo, fue uno de los argumentos más relevantes en la negociación del TLC, al igual que durante la campaña del referéndum, con lo que el postulado trabajo para todos los costarricenses parece quedar como una promesa de campaña que aún no se materializa.

Palabras clave: Migración interna; Tratado de Libre Comercio; población; expulsión; atracción y retorno

\section{Profile of Internal Migration in Costa Rica pre and post Approval Dominican Republic-Central America Free Trade Agreement}

Abstract: This paper focuses on the analysis of census data for the 2000 and 2011 round; for the characterization of the profile of internal migration before and after the approval in Costa Rica of the CAFTA. The results show that in migratory flows, as well as in migratory stages, no significant differences were found in the results obtained. Historically in the study of migrations. employment is one of the main reasons for population mobility; It was also one of the most relevant arguments in the negotiation of CAFTA, as well as during the referendum campaign, the sentence postulated "work for all Costa Ricans" seems to be a promise of campaign that still does not

Key words: Internal migration; CAFTA; population; expulsion; attraction and 


\section{Introducción}

Este artículo se enmarca en la iniciativa de profundizar acerca de la contemporaneidad de las migraciones internas en Costa Rica, a partir del análisis de los datos de movilidad poblacional recolectados durante el censo Nacional de Población de 2000 y 2011.

Se seleccionó este periodo censal específico considerando que la aprobación del Tratado de Libre Comercio (TLC) entre Estados Unidos, Centroamérica y República Dominicana se llevó a cabo en 2007; por lo cual se abarca un periodo de 5 años de su vigencia; y además que representa un hito en la historia política reciente de Costa Rica.

La aprobación del llamado TLC en Costa Rica fue un proceso político convulso que durante al menos dos años se mantuvo en constante discusión de forma previa a su aprobación; incluso, es recordado como el hecho más reciente por el que se llegó a convocar a un referéndum en la vida política oficial del país.

EI TLC tuvo por bandera durante la campaña previa al referéndum la apertura comercial como la principal fuente para generar nuevos empleos en el país, argumentando que se incrementarían las exportaciones, que llegarían nuevas empresas a invertir al país, y crecerían los emprendedurismos nacionales; y, por ende, mejorarían las condiciones de desarrollo para todo el país.

El empleo se reconoce como el principal motivo migratorio, razón por la cual, la puesta en marcha del TLC y sus promesas deberían de haber generado variaciones en las dinámicas migratorias internas del país, comprendidas a partir de dos elementos básicos como: los flujos migratorios, y las etapas migratorias. Por lo que el objetivo de esta investigación es caracterizar la dinámica de migración interna en el país durante el periodo 2001-2011 según las regiones socioeconómicas.

Para este estudio, se trabaja un análisis cuantitativo de los datos de población, a partir de las preguntas censales de lugar de nacimiento, residencia hace 5 años y residencia actual, con el objetivo de caracterizar las etapas migratorias de la población costarricense en el periodo censal de2000 y 2011 de acuerdo a las regiones socioeconómicas.

\section{Contextualización sobre el TLC}

Para el periodo de campaña previa al referéndum sobre el TLC existían distintos argumentos para posicionarse en favor o en contra del él; sin embargo, 
el empleo y la inversión extranjera como fuente generadora de este; siempre fue parte de la discusión, tal como lo señala Vargas:

El arma principal que utiliza la propaganda a favor del TLC es, sin duda, el empleo. El mensaje así lanzado se bifurca en dos vertientes, que se complementan y refuerzan mutuamente. Primero, se dice que el TLC permitirá atraer inversión extrajera con lo cual se crearán mayor cantidad de puestos de trabajo. Segundo, se afirma que la no aprobación del tratado pondrá en riesgo las exportaciones a Estados Unidos y, en general, hará que el país sea menos atractivo para la inversión extranjera, de modo que tendremos menos trabajo para nuestra gente (2007, 4).

Para aquel momento coyuntural de discusión sobre el TLC se señalaba constantemente por parte de las personas partidarias del "Sí al TLC" que su aprobación era indispensable, de lo contrario sería probable que disminuiría la inversión extranjera y se perderían potenciales empleos para el país; además de recalcar las dificultades para colocar las exportaciones de Costa Rica en los Estados Unidos.; en relación con este tema se menciona que:

No hace falta saber mucho de economía para captar la gravísima contradicción en que el neoliberalismo tiene atrapado a nuestro país. Véase qué claro: las inversiones extranjeras crecen espectacularmente así como las exportaciones. Otro tanto acontece con la producción nacional medida por el PIB. Y, sin embargo, escasean grave, pero muy gravemente, los empleos de calidad. Seiscientos y resto de mil trabajadores y trabajadoras costarricenses que, a julio de 2006, estaban desempleados o subempleados, constituye mucho, pero mucho más que una fría estadística. He ahí un drama social y humano que envilece y maltrata.

Sobre todo debe quedar clara una cosa: la inversión que nos llega por parte de las corporaciones transnacio- 
nales -en especial las de alta tecnología- aporta una proporción sustancial de las exportaciones pero una cuota absolutamente despreciable del empleo. Y, en contrapartida, su emplazamiento en Costa Rica implica grandes costos, en términos de los privilegios fiscales y el apoyo institucional que se les concede, así como de la infraestructura pública con que se les provee (Vargas 2007, 1920).

A pesar de estas condiciones mencionadas como parte del contexto coyuntural en torno a las negociaciones, aprobación y referéndum del tratado; el tema del empleo no deja de ser de importancia en el marco de estas negociaciones internacionales; sin embargo el enfoque que se brinda al tema no hace referencia explícita a la cantidad de empleos estimados a generar; sino que se plantea de forma muy específica en torno al cumplimiento de la reglamentación de las normativas laborales de cada país, así como las normativas ratificadas a nivel internacional.

Justamente en relación con lo anterior, según indica el Estado de la Nación (2005, p209) lo aprobado en el TLC, acordaba lo siguiente:

1. Reafirmar las obligaciones como miembros de la OIT y los compromisos asumidos en la Declaración de la OIT.

2. Comprometerse a no debilitar ni reducir la protección laboral existente (con el objetivo de promover el comercio o la inversión).

3. Establecer un Consejo de Asuntos Laborales a nivel ministerial.

4. Establecer un Mecanismo de Cooperación Laboral y Desarrollo de Capacidades.

5. Realización de Consultas Laborales Cooperativas.

Sí bien, el señalamiento del respeto a los derechos sociolaborales de la población es de innegablemente importante y necesario en el marco de estos tratados; la discusión de los argumentos a favor o en contra del tratado vinculado al empleo se fundamenta en la cantidad, pero más allá también en la calidad de empleos disponibles y futuros en el país.

De acuerdo con lo anterior, según señala Fallas (2012) como referencia, las condiciones laborales en el país para el 2007 marcaban un desempleo abierto de 4,6\%; mientras que para el 2011 ya había alcanzado el 7,7\%; según datos del Instituto Nacional de Estadística y Censos (INEC); por lo tanto, "se considera que si pudo haberse aumentado el desempleo abierto por el menor crecimiento de la producción y de las exportaciones y la fallida apuesta por el mercado de Estados Unidos" (Fallas 2012, 3).; según datos de INEC (2018) 
para el I trimestre de ese año se alcanzó una tasa de 10,26 personas desempleadas por cada 100 personas de la Fuerza de Trabajo.

De forma tal que con la aprobación del TLC se plantearon una serie de expectativas al país con respecto a empleo; sin embargo, estas no han sido concretadas por condiciones estructurales asociadas al modelo de desarrollo económico en el que se encuentra inmerso el país, como ya lo señalaba el Movimiento No (2007), de forma previa a su aprobación:

La inversión extranjera es importante pero no es la única ni la principal generadora de empleo. Desde 1994 las inversiones de Costa Rica aumentaron cinco veces. Pero el desempleo también aumentó y ahora los trabajos informales (mal pagados y sin seguro social) son más de la mitad de los nuevos empleos creados cada año. Las empresas de Zona Franca acapararan la mayor cantidad de inversión extranjera y exportación del país, pero solo emplean 2 de cada 100 personas ocupadas, el mismo empleo que ofrece un solo sector nacional: el lechero (Movimiento No 2007, 5).

\section{Metodología}

La principal fuente de información para llevar a cabo esta investigación fueron las bases de datos de los Censos Nacionales de Población IX y X, proporcionada por el INEC de Costa Rica.

Para abordar el tema de la migración interna se debe tener claridad de su González, en alusión a la definición del Diccionario Demográfico Multilingüe de la Unión Internacional para el Estudio Científico de la Población (iTtECP) señala:

Se da el nombre de migración o movimiento migratorio, al desplazamiento, con traslado de residencia de los individuos, desde un lugar de origen a un lugar de destino o llegada y que implica atravesar los límites de una división geográfica (González 2011, 5). 
Por lo anterior, se lleva a cabo un análisis cuantitativo de los datos de población correspondientes para la caracterización de las etapas migratorias internas de la población costarricense durante el periodo censal del 2000 y del 2011, según las regiones socioeconómicas del país. Para la comprensión del término etapas migratorias, se consideraron los siguientes aspectos:

Tabla 1. Construcción metodológica del concepto Etapas Migratorias

\begin{tabular}{|c|c|c|}
\hline $\begin{array}{l}\text { Dimensión de } \\
\text { análisis }\end{array}$ & Operacionalización variable & Variables \\
\hline Etapas migratorias & $\begin{array}{l}\text { Corresponde a la etapa de } \\
\text { vida, relacionada a la } \\
\text { movilidad poblacional en la } \\
\text { que se encuentra la persona } \\
\text { en un periodo censal } \\
\text { específico. }\end{array}$ & $\begin{array}{l}\text { No migrante } \\
\text { Posible migrante } \\
\text { En proceso migratorio } \\
\text { (reciente/antiguo) } \\
\text { Migrante en retorno }\end{array}$ \\
\hline
\end{tabular}

Elaboración propia.

Para el caso de la dimensión de análisis etapa migratoria, se propone el uso de un indicador que permita determinar las etapas relacionadas a la movilidad poblacional; fundamentalmente basada en la clasificación básica de los desplazamientos en la línea planteada por George Tapinos (1985), a fin de contribuir en el análisis del perfil migratorio de una población determinada en un periodo censal específico.

Los insumos de datos censales para la construcción de este indicador se basan en los resultados obtenidos en tres preguntas empleadas en el cuestionario censal, referentes al movimiento de la población en distintos momentos de la vida de cada persona durante ese periodo censal específico.

Figura 1. Pregunta 1 Residencia actual
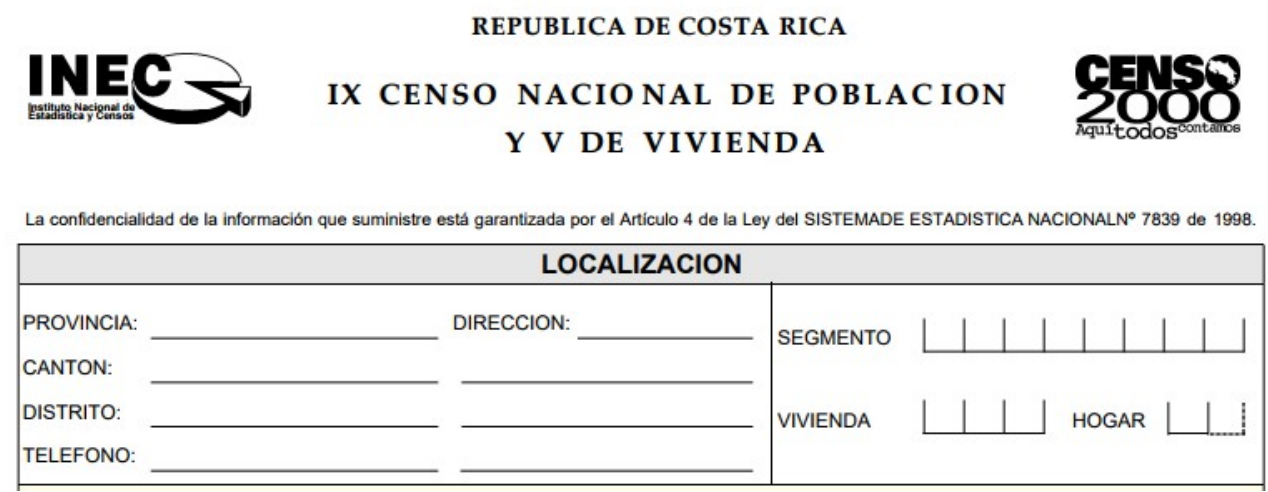

Cuestionario Censal, IX Censo Nacional de Población y vivienda, 2000 
Figura 2. Pregunta 2 Residencia hace 5 años

\section{PARA PERSONAS DE 5 AÑOS O MAS}

9. ¿Dónde vivía en junio de $1995 ?$

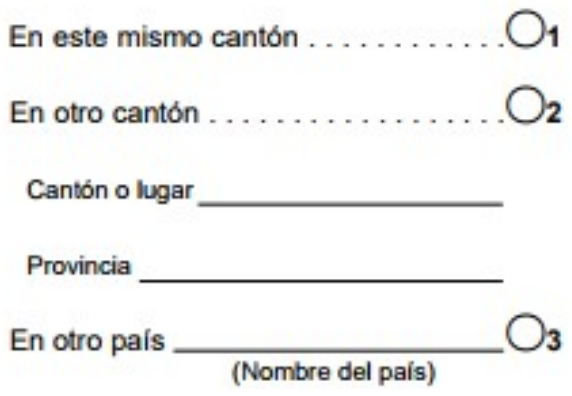

Cuestionario Censal, IX Censo Nacional de Población y vivienda, 2000

Figura 3. Pregunta 3 Residencia al nacimiento

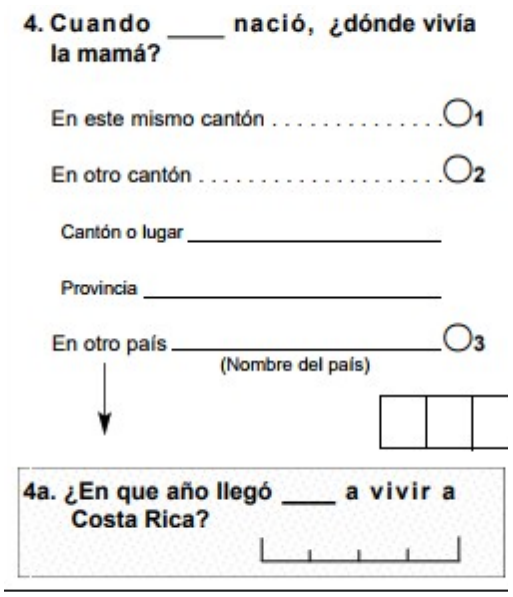

Cuestionario Censal, IX Censo Nacional de Población y vivienda, 2000

A partir de la valoración de las preguntas anteriores que fungen como insumo para la construcción del indicador, se determina que la estructura de las opciones de respuesta se repite para la pregunta número 4 y para la pregunta número 9 del cuestionario; empero, es distinta para la pregunta referente a la localización actual; razón por la cual se planteó la generación de una nueva variable en la base de datos denominada "Dirección actual recodificada", que recodifica las respuestas obtenidas en la pregunta inicial. 
Tabla 2. Construcción de nueva variable "Dirección actual recodificada"

\begin{tabular}{|c|c|}
\hline Categorías de respuesta inicial & Categorías de respuesta recodificada \\
\hline $\begin{array}{ll}\text { - } & \text { Provincia } \\
\text { - } & \text { Cantón } \\
\text { - } & \text { Distrito }\end{array}$ & $\begin{array}{l}\text { - } \quad \text { Mismo cantón nacimiento } \\
\text { - } \quad \text { Otro cantón de residencia actual } \\
\text { Mismo cantón de residencia hace } 5 \\
\text { años }\end{array}$ \\
\hline $\begin{array}{l}\text { 1. Se excluyen los casos de } \\
\text { 2. Se contrasta con las re } \\
\text { determinar la recodificaci }\end{array}$ & $\begin{array}{l}\text { antos en otro país. } \\
\text { as obtenidas en preguntas } 4 \text { y } 9 \text { para }\end{array}$ \\
\hline
\end{tabular}

Elaboración Propia

Una vez creada la nueva variable en la base de datos se ha unificado el formato de respuesta para las tres preguntas seleccionadas para la construcción del indicador; con lo que se crea una nueva variable denominada "Categoría migrante", que contempla tres momentos específicos la residencia al nacimiento, la residencia de hace 5 años y la residencia actual; con lo que la nueva variable consiste en identificar patrones de recurrencia en las respuestas brindadas por cada informante, de forma tal que puedan ser clasificadas de la siguiente forma:

Tabla 3. Construcción metodológica indicador categoría migrante

\begin{tabular}{llll}
\hline Categoría de migrante & $\begin{array}{c}\text { Residencia al } \\
\text { nacimiento }\end{array}$ & $\begin{array}{l}\text { Residencia de } \\
\text { hace } \mathbf{5} \text { años }\end{array}$ & $\begin{array}{l}\text { Residencia } \\
\text { actual }\end{array}$ \\
\hline No migrante & $\begin{array}{l}\text { Cantón de } \\
\text { nacimiento }\end{array}$ & $\begin{array}{l}\text { Mismo cantón } \\
\text { nacimiento }\end{array}$ & $\begin{array}{l}\text { Mismo cantón } \\
\text { nacimiento }\end{array}$ \\
\hline Migrante reciente & $\begin{array}{l}\text { Cantón de } \\
\text { nacimiento }\end{array}$ & $\begin{array}{l}\text { Mismo cantón } \\
\text { nacimiento }\end{array}$ & $\begin{array}{l}\text { Otro cantón de } \\
\text { residencia } \\
\text { actual }\end{array}$ \\
\hline Migrante antiguo & $\begin{array}{l}\text { Cantón de } \\
\text { nacimiento }\end{array}$ & $\begin{array}{l}\text { Otro cantón de } \\
\text { residencia }\end{array}$ & $\begin{array}{l}\text { Mismo cantón } \\
\text { de residencia } \\
\text { hace 5 años }\end{array}$ \\
\hline Migrante en retorno & $\begin{array}{l}\text { Cantón de } \\
\text { nacimiento }\end{array}$ & $\begin{array}{l}\text { Otro cantón de } \\
\text { residencia }\end{array}$ & $\begin{array}{l}\text { Mismo cantón } \\
\text { de nacimiento }\end{array}$ \\
\hline
\end{tabular}

Elaboración propia

La construcción de la nueva variable "Categoría de migrante" permite la posibilidad de analizar esta clasificación con otras variables existentes en la base de datos, lo cual amplía a nivel metodológico el análisis de la migración interna en el país. Incorporando la identificación del migrante en retorno al incluir 
el dato de residencia al nacimiento; así como el proceso migratorio en dos clasificaciones el reciente para aquellos que se movilizaron en los últimos cinco años; y antiguo para quien indicó más de un movimiento en el periodo censal; a su vez clasifica al no migrante como aquella persona que no tuvo cambio de domicilio durante el tiempo de estudio.

\section{Resultados}

A partir de la construcción de este índice para la clasificación de la categoría migratoria a nivel interno, se logró tener un dato a nivel nacional, con el fin de identificar los resultados obtenidos. Se toma en cuenta que al contener en su composición las tres preguntas censales permiten comparar los tres momentos de la vida de cada persona residente en los hogares censados.

Tabla 4. Categoría migrante interno a nivel país 2000-2011

\begin{tabular}{ccccc}
\hline Año & $\begin{array}{c}\text { \% No } \\
\text { Migrante }\end{array}$ & $\begin{array}{c}\text { \% Migrante } \\
\text { Reciente }\end{array}$ & $\begin{array}{c}\text { \% Migrante } \\
\text { Antiguo }\end{array}$ & $\begin{array}{c}\text { \% Migrante } \\
\text { en Retorno }\end{array}$ \\
\hline $\mathbf{2 0 1 1}$ & 62.72 & 27.27 & 8.04 & 1.96 \\
$\mathbf{2 0 0 0}$ & 61.50 & 28.18 & 8.76 & 1.56 \\
\hline
\end{tabular}

Elaboración Propia.

Para los datos nacionales se observa que aproximadamente el $61,50 \%$ en el 2000 y un $62,72 \%$ para el 2011 , de la población no ha presentado movimiento de residencia a nivel cantonal, con tan solo una diferencia de 1,22\% entre ambos periodos; además, se identifica que un 36,92\% de la población indica encontrarse en un proceso migratorio para el año 2000; mientras que para el 2011 ascendía a 37,27\%; específicamente con una diferencia de $-0,91 \%$ en la migración de forma reciente, mientras que un -0,72 de forma antigua; para finalizar únicamente $0,4 \%$ de la población de migrante en retorno.

Para la construcción de este índice se contempló la definición de migración desde el concepto de movilidad de residencia en las unidades cantonales pertenecientes a regiones socioeconómicas del país, considerando que este elemento es de suma importancia para los estudios migratorios.

Los datos de migración interna para áreas pequeñas son de interés para diversas instituciones, tanto públicas como privadas porque permiten conocer uno de los factores más importantes del crecimiento poblacional del área 
y prever el impacto que los migrantes pueden tener sobre la demanda de servicios educativos, de salud, de agua, electricidad, etc., y en general sobre la actividad económica del área. En el caso de Costa Rica, dado el papel que juega el cantón como unidad administrativa de gobierno local, la medición de la migración usándolo como referencia adquiere especial importancia (Gómez y Madrigal 2004, 511).

Usualmente estos estudios trabajan con la clasificación, provincia, cantón; no obstante, es de relevancia desde el análisis de las motivaciones migratorias considerando el empleo como el más relevante, en adición de la posibilidad de trabajar por regiones socioeconómicas dado que estas a su vez están compuestas por los cantones; pero cada una de ellas presenta características particulares acorde a las dinámicas de desarrollo a nivel social y económico-productivo.

Desde el INEC se han clasificado siete regiones socioeconómicas del país: Región Área metropolitana, Resto de la Región Central, Región Chorotega, Región Pacífico Central, Región Brunca, Región Huetar Atlántica y Región Huetar Norte; a continuación, se muestran los resultados obtenidos mediante el indicador según región socioeconómica:

Tabla 5. Indicador categoría migrante interno según región socioeconómica 2000-2011

\begin{tabular}{|c|c|c|c|c|c|c|c|c|c|c|c|c|c|c|}
\hline \multirow[b]{3}{*}{ No migrante } & \multirow{2}{*}{\multicolumn{2}{|c|}{ 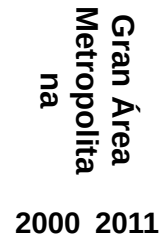 }} & \multicolumn{2}{|c|}{ 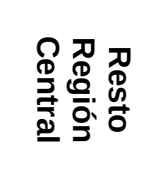 } & \multicolumn{2}{|c|}{ 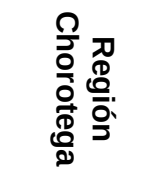 } & \multicolumn{2}{|c|}{ 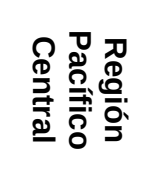 } & \multicolumn{2}{|c|}{ 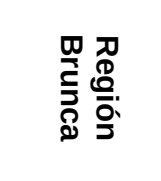 } & \multicolumn{2}{|c|}{ 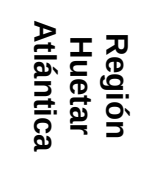 } & \multicolumn{2}{|c|}{ 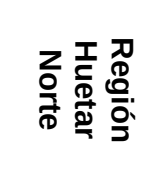 } \\
\hline & & & 2000 & 2011 & 2000 & 2011 & 2000 & 2011 & 2000 & 2011 & 200 & 2011 & 2000 & 2011 \\
\hline & $\begin{array}{c}51.2 \\
\%\end{array}$ & $\begin{array}{c}58.0 \\
\%\end{array}$ & $\begin{array}{c}66.1 \\
\%\end{array}$ & $\begin{array}{c}75.0 \\
\%\end{array}$ & $\begin{array}{c}74.5 \\
\%\end{array}$ & $\begin{array}{c}72.0 \\
\%\end{array}$ & $\begin{array}{c}68.0 \\
\%\end{array}$ & $\begin{array}{c}67.6 \\
\%\end{array}$ & $\begin{array}{c}63.7 \\
\%\end{array}$ & $\begin{array}{c}66.2 \\
\%\end{array}$ & $\begin{array}{c}52.5 \\
\%\end{array}$ & $\begin{array}{c}59.5 \\
\%\end{array}$ & $\begin{array}{c}64.2 \\
\%\end{array}$ & $\begin{array}{c}62.8 \\
\%\end{array}$ \\
\hline $\begin{array}{l}\text { Migrante } \\
\text { reciente }\end{array}$ & $\begin{array}{c}36.8 \\
\%\end{array}$ & $\begin{array}{c}30.8 \\
\%\end{array}$ & $\begin{array}{c}24.1 \\
\%\end{array}$ & $\begin{array}{c}17.9 \\
\%\end{array}$ & $\begin{array}{c}17.5 \\
\%\end{array}$ & $\begin{array}{c}18.9 \\
\%\end{array}$ & $\begin{array}{c}23.2 \\
\%\end{array}$ & $\begin{array}{c}23.3 \\
\%\end{array}$ & $\begin{array}{c}27.2 \\
\%\end{array}$ & $\begin{array}{c}25.7 \\
\%\end{array}$ & $\begin{array}{c}35.5 \\
\%\end{array}$ & $\begin{array}{c}31.1 \\
\%\end{array}$ & $\begin{array}{c}26.3 \\
\%\end{array}$ & $\begin{array}{c}26.7 \\
\%\end{array}$ \\
\hline $\begin{array}{l}\text { Migrante } \\
\text { antiguo }\end{array}$ & $\begin{array}{c}10.4 \\
\%\end{array}$ & $\begin{array}{c}9.3 \\
\%\end{array}$ & $\begin{array}{c}8.6 \\
\%\end{array}$ & $\begin{array}{c}5.6 \\
\%\end{array}$ & $\begin{array}{c}5.8 \\
\%\end{array}$ & $\begin{array}{c}6.8 \\
\%\end{array}$ & $\begin{array}{c}6.9 \\
\%\end{array}$ & $\begin{array}{c}7.2 \\
\%\end{array}$ & $\begin{array}{c}7.0 \\
\%\end{array}$ & $\begin{array}{c}5.9 \\
\%\end{array}$ & $\begin{array}{c}10.7 \\
\%\end{array}$ & $\begin{array}{c}7.6 \\
\%\end{array}$ & $\begin{array}{c}7.8 \\
\%\end{array}$ & $\begin{array}{c}8.3 \\
\%\end{array}$ \\
\hline $\begin{array}{l}\text { Migrante en } \\
\text { retorno }\end{array}$ & $\begin{array}{c}1.6 \\
\%\end{array}$ & $\begin{array}{c}2.0 \\
\%\end{array}$ & $\begin{array}{c}1.3 \\
\%\end{array}$ & $\begin{array}{c}1.6 \\
\%\end{array}$ & $\begin{array}{c}2.2 \\
\%\end{array}$ & $\begin{array}{c}2.3 \\
\%\end{array}$ & $\begin{array}{c}1.9 \\
\%\end{array}$ & $\begin{array}{c}1.9 \\
\%\end{array}$ & $\begin{array}{c}2.1 \\
\%\end{array}$ & $\begin{array}{c}2.1 \\
\%\end{array}$ & $\begin{array}{c}1.3 \\
\%\end{array}$ & $\begin{array}{c}1.8 \\
\%\end{array}$ & $\begin{array}{c}1.6 \\
\%\end{array}$ & $\begin{array}{c}2.2 \\
\%\end{array}$ \\
\hline
\end{tabular}

Elaboración propia 
A partir de la información obtenida sobre las categorías de migrante interno, se identificó la importancia de observar tres momentos específicos dentro del proceso migratorio, por lo cual se observará la tasa de emigración, la tasa de inmigración y el porcentaje de población en retorno para identificar los procesos de expulsión, atracción y retorno en las distintas regiones socioeconómicas del país.

\section{La emigración}

La migración conceptualmente puede asociarse a un proceso; según manifiesta León (2005), la emigración es el primer paso y este consiste justamente con el abandono de una persona o un grupo de personas de su lugar de origen por un tiempo prolongado hacia otro lugar de forma indefinida.

Por consiguiente, la emigración se asocia metodológicamente con el registro de la movilidad del lugar de origen; es decir, a la que hasta entonces era considerada la residencia permanente, a un nuevo lugar de residencia; directamente, esto permite la identificación de los posibles focos de expulsión de población de una localidad geográfica determinada.

Tabla 6. Tasa de emigración a nivel interno, según región socioeconómica 2000-2011

\begin{tabular}{lcc}
\hline Tasa de emigración & $\mathbf{2 0 0 0}$ & $\mathbf{2 0 1 1}$ \\
\hline Área Metropolitana & 10.02 & 10.00 \\
Resto Región Central & 6.50 & 5.42 \\
Región Chorotega & 7.07 & 8.29 \\
Región Pacífico Central & 6.16 & 7.66 \\
Región Brunca & 5.58 & 5.41 \\
Región Huetar Atlántica & 9.43 & 8.82 \\
Región Huetar Norte Atlántica & 10.61 & 12.79 \\
\hline
\end{tabular}

Elaboración propia

Para el caso costarricense, tanto para el periodo censal 2000 y 2011, se observa claramente que las regiones de más expulsión para el año 2000 son el Área Metropolitana, la Región Huetar atlántica y la Región Huetar Norte, con tasas de emigración de 10,02, 9,43 y 10.61, respectivamente, por cada 1000 habitantes; mientras que para el 2011 son el Área Metropolitana, la Región Huetar Atlántica y la Región Huetar Norte, con tasas de emigración de 10.00, 8.82 y 12,79 , en el mismo orden, por cada 1000 habitantes, lo cual representa una leve diferencia entre un periodo censal y el otro, como se muestra en los Mapas 1 y 2. 
Mapa 1. Tasa de emigración por región socioeconómica en Costa Rica, 2000

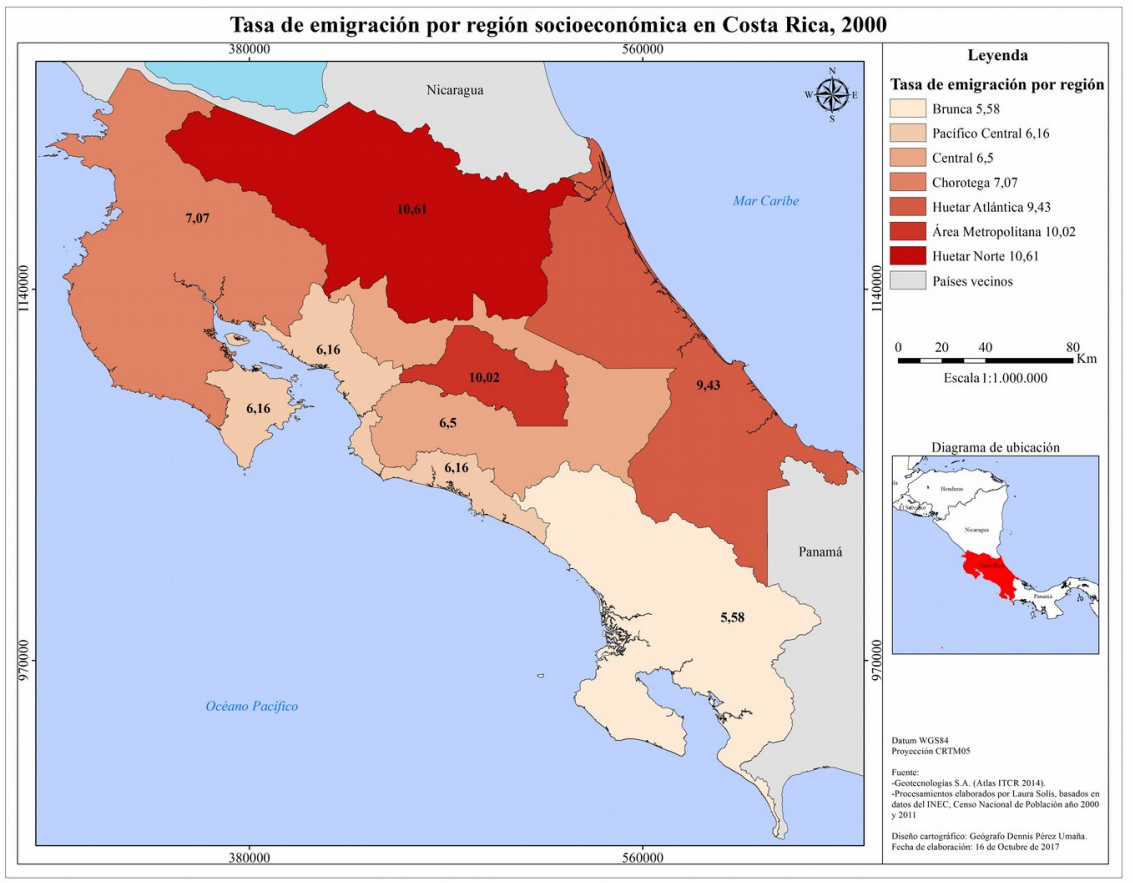

Elaboración propia. Diseño cartográfico Dennis Pérez Umaña.

Mapa 2. Tasa de Emigración por Región Socioeconómica en Costa Rica, 2011

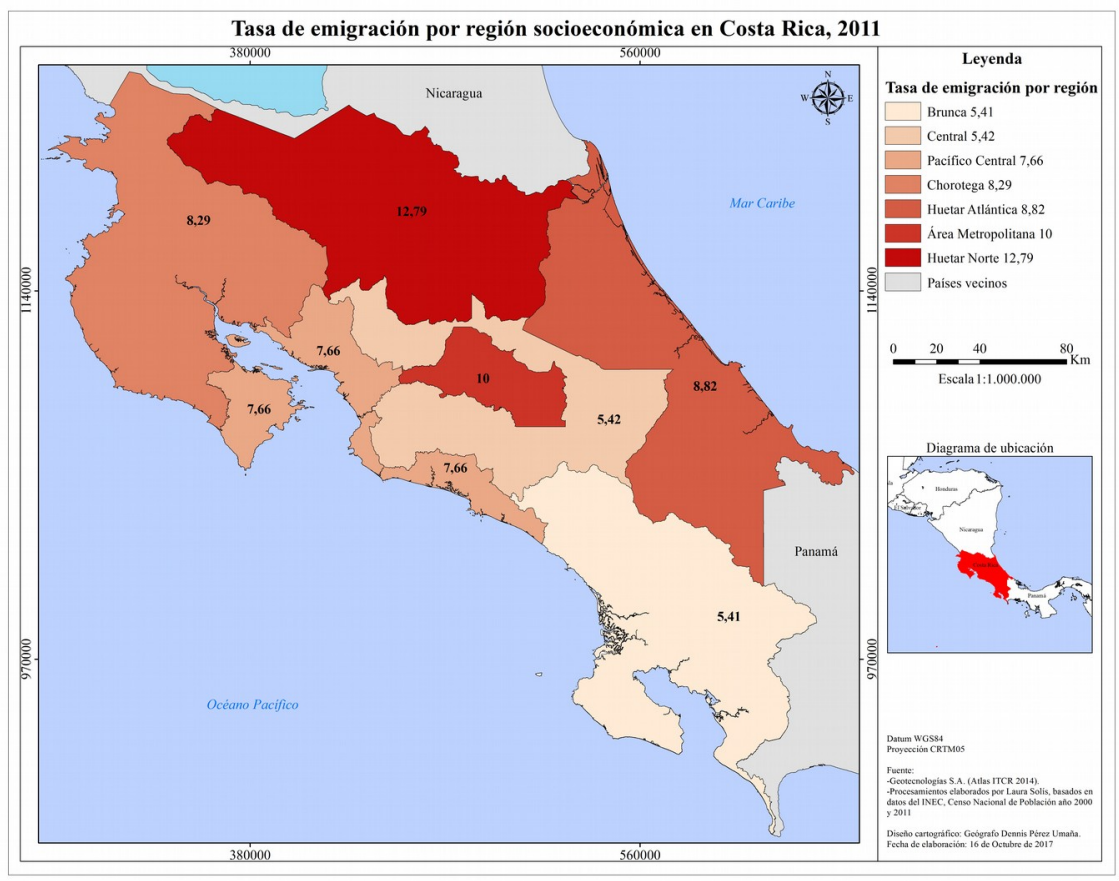

Elaboración propia. Diseño cartográfico Dennis Pérez Umaña. 


\section{La inmigración}

El concepto de inmigración, según señala León (2005), implica el asentamiento de una población proveniente de otro espacio geográfico en una nueva comunidad; o sea, una de las comunidades funge el papel de emisora, mientras que la otra tiene el rol de receptora.

La configuración de una región socioeconómica como polo migratorio de atracción de población implica características particulares que generan esas condiciones de interés por asentarse en ese espacio; de forma frecuente, esto podría ser asociado a motivos laborales.

Tabla 7. Tasa de inmigración a nivel interno, según región socioeconómica 2000-2011

\begin{tabular}{lcc}
\hline \multicolumn{1}{c}{ Tasa de inmigración } & $\mathbf{2 0 0 0}$ & $\mathbf{2 0 1 1}$ \\
\hline Área Metropolitana & 5.74 & 5.36 \\
Resto Región Central & 4.85 & 3.51 \\
Región Chorotega & 3.84 & 4.37 \\
Región Pacífico Central & 4.31 & 4.38 \\
Región Brunca & 4.51 & 3.95 \\
Región Huetar Atlántica & 5.79 & 4.52 \\
Región Huetar Norte & 4.43 & 4.81 \\
\hline
\end{tabular}

Elaboración propia.

Mapa 3. Tasa de inmigración por Región Socioeconómica en Costa Rica, 2000

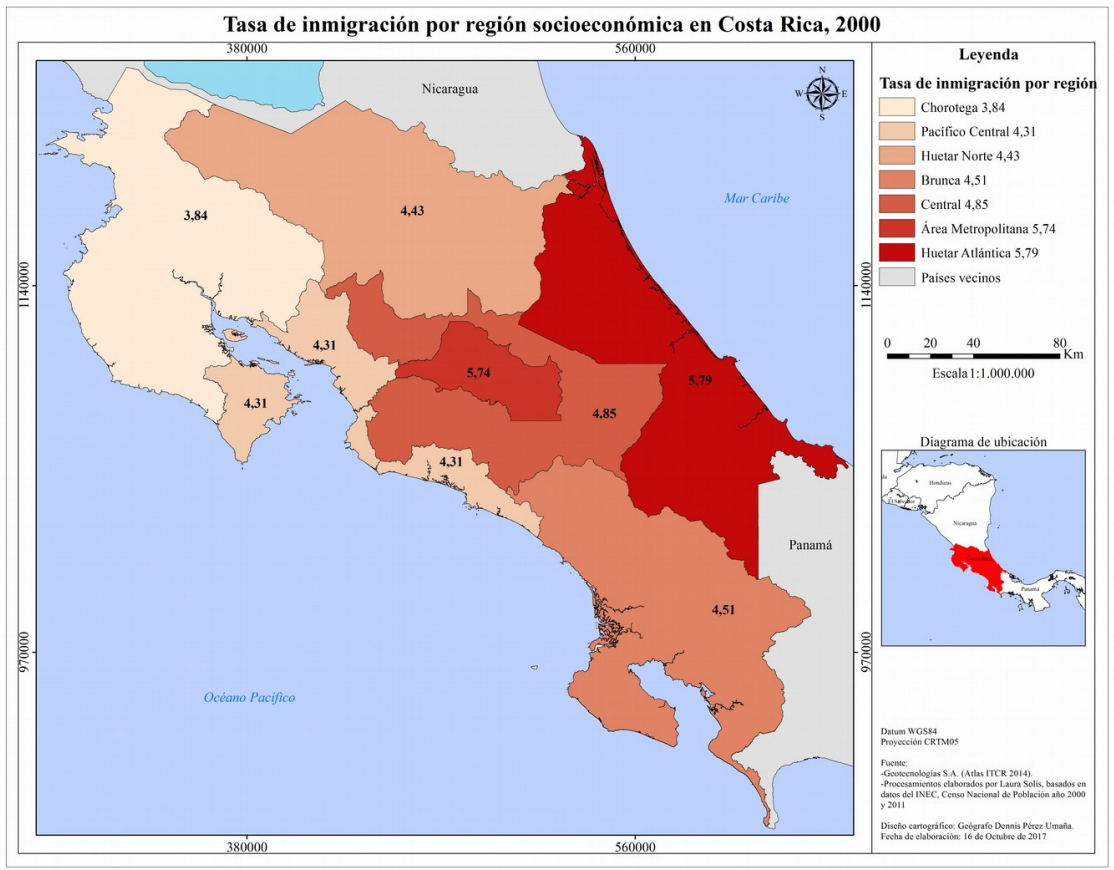

Elaboración propia. Diseño cartográfico Dennis Pérez Umaña. 
Para el caso en estudio, tanto para el periodo censal 2000 y 2011, se observa claramente que las regiones de mayor atracción para el 2000 son el Área Metropolitana, la Región Huetar Atlántica y la Región Huetar Norte, con tasas de inmigración de 5,74, 5,79 y 4.43, respectivamente, por cada 1000 habitantes; mientras que para el 2011 son el Área Metropolitana, la Región Huetar Atlántica y la Región Huetar Norte, con tasas de emigración de 5,36, 4.52 y 4,81; respectivamente, por cada 1000 habitantes, lo cual representa una leve diferencia entre un periodo censal y el otro.

Mapa 4. Tasa de inmigración por Región Socioeconómica en Costa Rica, 2011

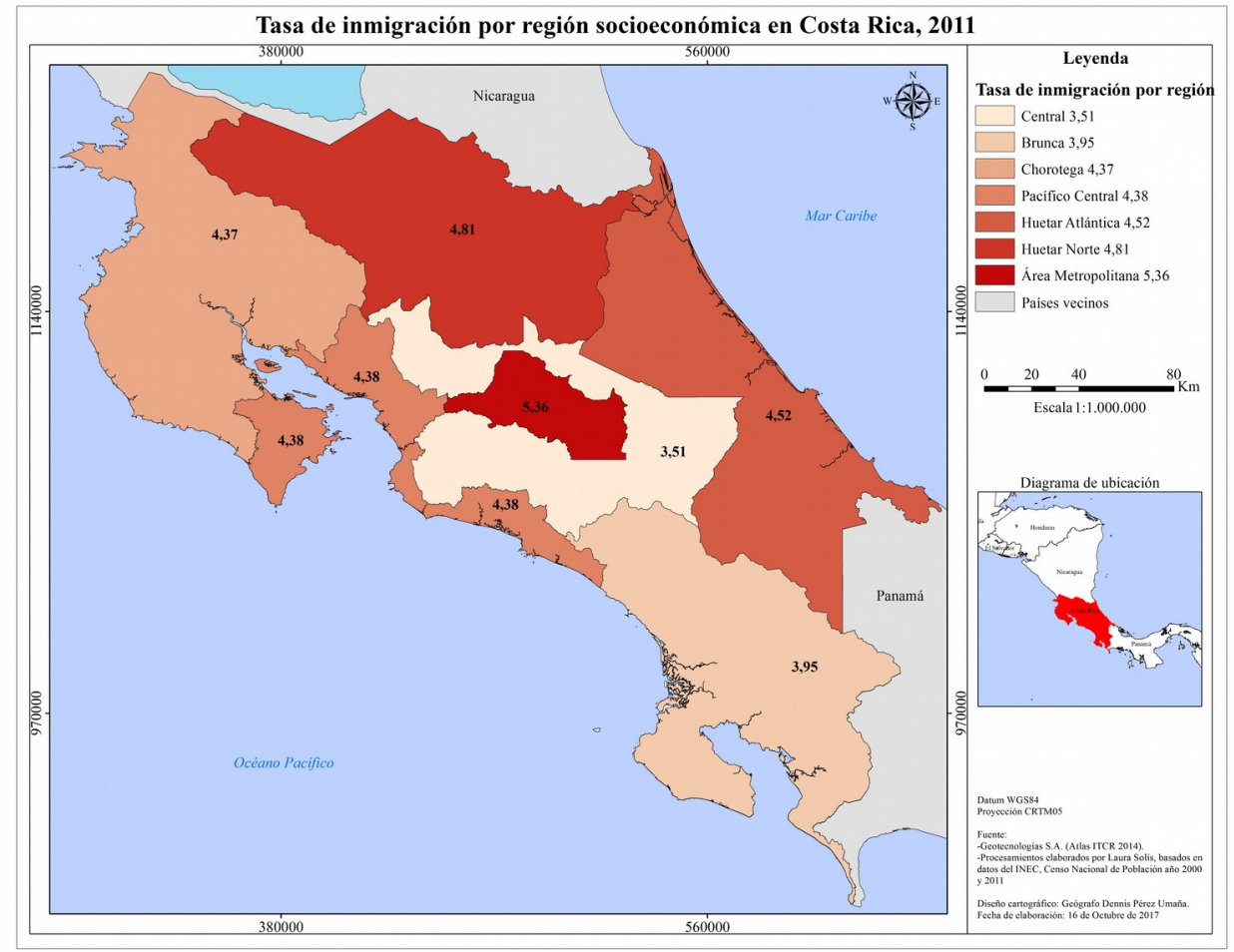

Elaboración propia. Diseño cartográfico Dennis Pérez Umaña.

\section{Retorno}

El retorno es una etapa más dentro del proceso migratorio. Si bien hay distintas posturas para su abordaje teórico, como lo señala León (2005), en las que podría visualizarse desde una perspectiva como un fracaso en el tanto refleja una migración no exitosa; a su vez podría ser considerado desde otra mirada como la concreción de objetivos asociados a la motivación de movilidad que señala las condiciones necesarias que permiten percibir justamente el retorno con una opción. 
Tabla 8. Porcentaje de retorno migración interna, según región socioeconómica 2000-2011

\begin{tabular}{lcc}
\hline \multicolumn{1}{c}{ \% de población en retorno } & $\mathbf{2 0 0 0}$ & $\mathbf{2 0 1 1}$ \\
\hline Área Metropolitana & 1.60 & 2.00 \\
Resto Región Central & 1.30 & 1.60 \\
Región Chorotega & 2.20 & 2.30 \\
Región Pacífico Central & 1.90 & 1.90 \\
Región Brunca & 2.10 & 2.10 \\
Región Huetar Atlántica & 1.30 & 1.80 \\
Región Huetar Norte Atlántica & 1.60 & 2.20 \\
\hline
\end{tabular}

Elaboración propia

Las regiones que presentan mayor tendencia al retorno, de acuerdo con el porcentaje de población retornada para cada región socioeconómica del país, para el periodo censal del año 2000, son Región Brunca, Región Chorotega y Región Pacífico Central con $2.08 \%$ y $2.09 \%$ y $1.9 \%$, en el mismo orden, por cada 1000 habitantes; mientras que para el caso del periodo censal del año 2011 destacan Región Brunca, Región Chorotega y Región Huetar Norte con $2.10 \%$ y $2.30 \%$ y $2.20 \%$, respectivamente, por cada 1000 habitantes; con lo cual se observa que a nivel general no se presenta gran variación en diferencias porcentuales entre las regiones socioeconómicas y los periodos de estudio.

\section{Mapa 5. Porcentaje de población en retorno, por Región Socioeconómica en}

\section{Costa Rica, 2000}

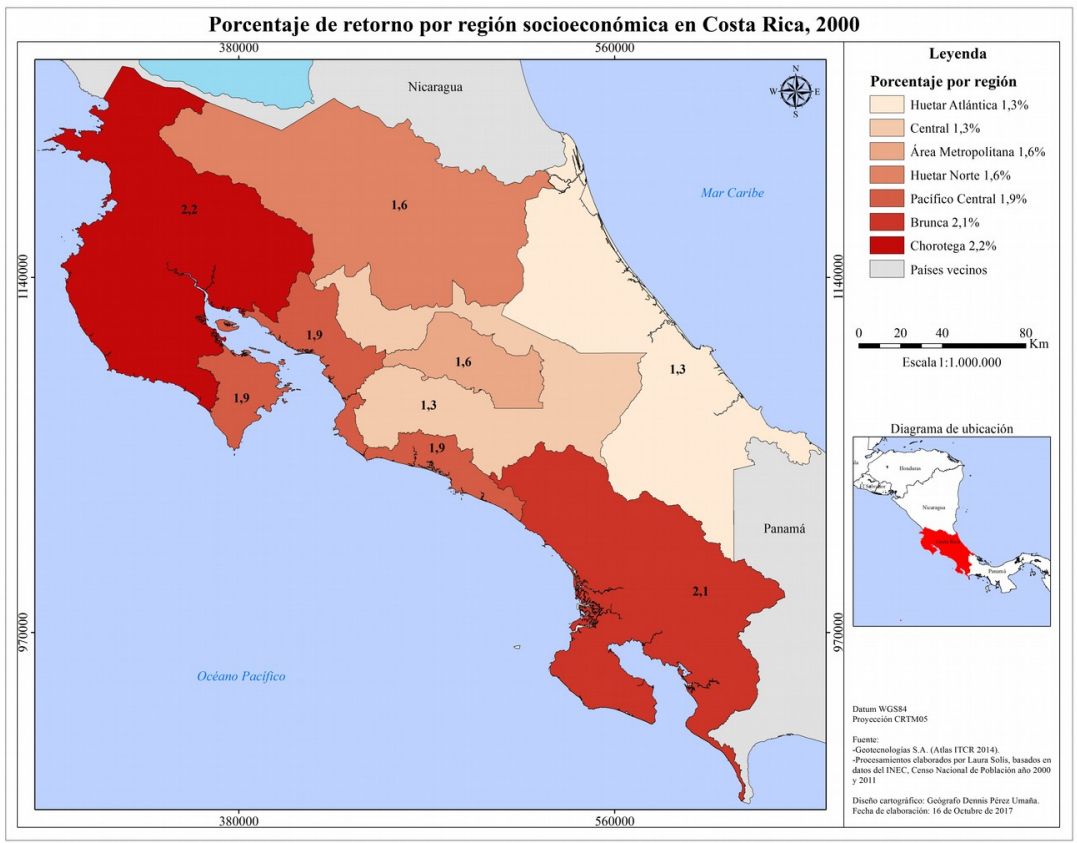

Elaboración propia. Diseño cartográfico Dennis Pérez Umaña. 
Mapa 6. Porcentaje de población en retorno, por Región Socioeconómica en Costa Rica, 2011

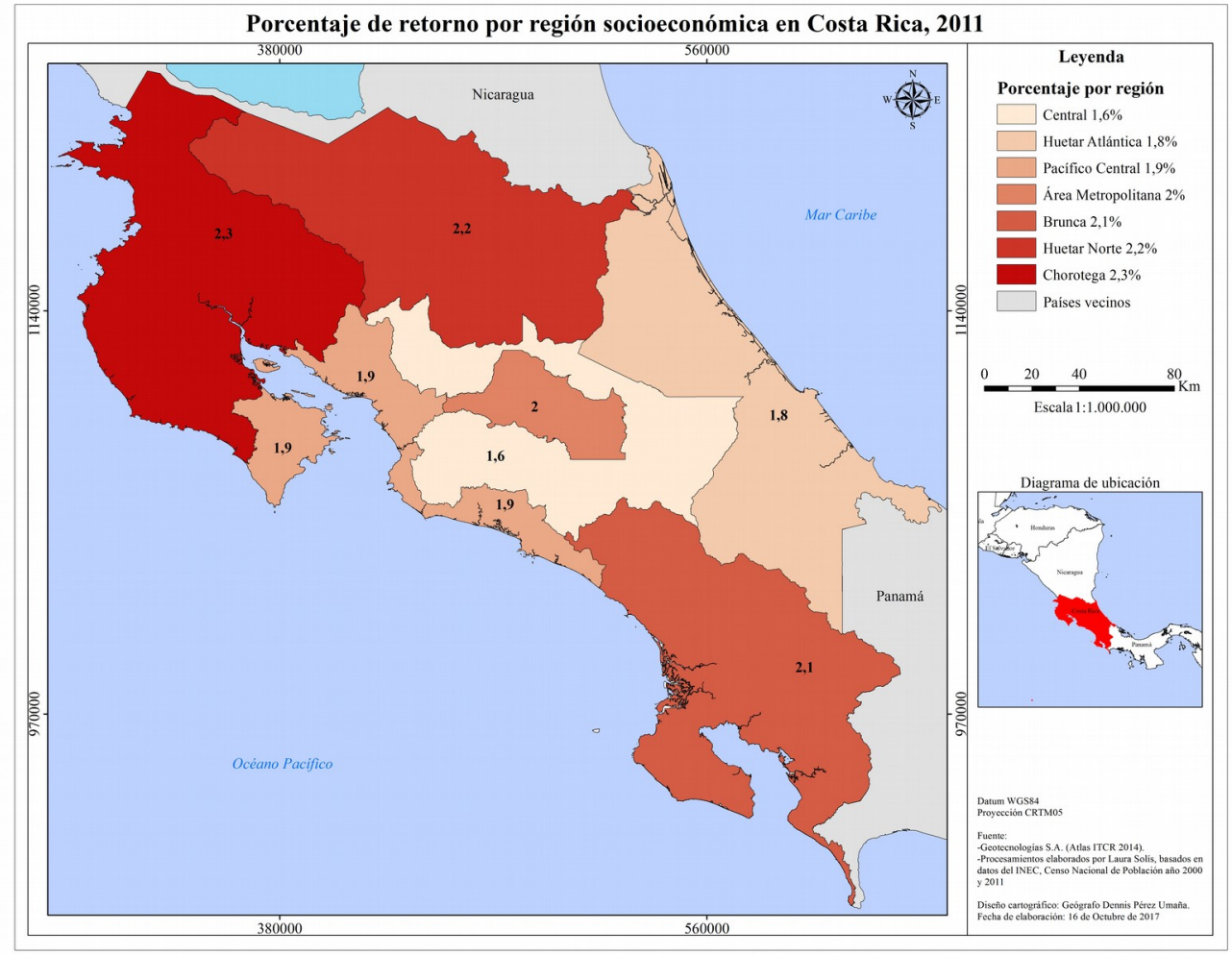

Elaboración propia. Diseño cartográfico Dennis Pérez Umaña.

\section{Estructura de la población migrante reciente 2011}

Tal como se señaló anteriormente, se conciben el proceso migratorio como la composición de determinadas etapas presentes en el proyecto migratorio de cada persona como parte de una población en su totalidad; para efectos de este artículo, resulta relevante profundizar en las características de la población que fue identificada en proceso migratorio reciente; es decir, durante los primeros cinco años de vigencia del TLC.

A partir de los datos censales del año 2011 y mediante el indicador planteado, se identificó como población migrante reciente a $28,18 \%$ de la población costarricense. 
Figura 4. Pirámide de la estructura de la población migrante reciente a nivel nacional, 2011

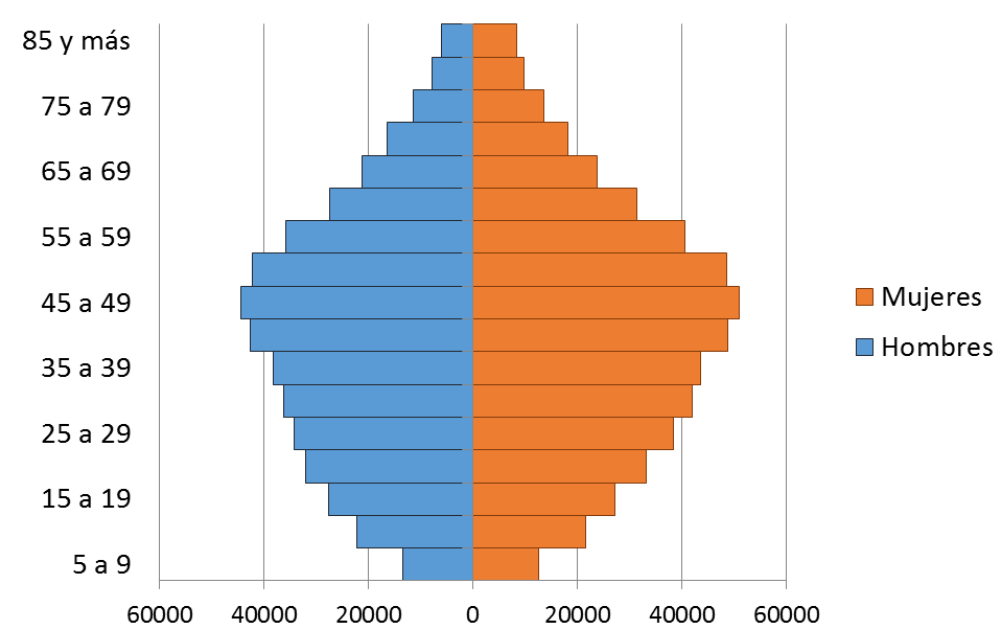

Elaboración propia.

Es posible observar en la pirámide la estructura de la población del país en etapa migratoria reciente para los distintos grupos etarios quinquenales de edad y según sexo.

Para este grupo poblacional en específico se observa una importante presencia de la población económicamente activa, la cual conceptualmente marca el rango de edades entre los 15 a los 65 años; a su vez, se denota la presencia de la migración femenina, en mayor número poblacional que en el caso de los hombres, considerando un índice de masculinidad de 88,93. La proporción regular es de 101 hombres por cada 100 mujeres.

La edad de 18 a 35 años es un periodo de la vida en la que muchas de las personas jóvenes se están incorporando a etapas laborales o de estudio universitario, que incentivan la migración interna como una forma de alcanzar metas de autorrealización; lo cual aún es más notorio en la estructura en regiones como la región central y el resto de la Región Central; dadas las características de desarrollo en cuanto a posibilidades de empleos de diversa índole profesional y no profesional; así como la ubicación espacial de las sedes centrales de las universidades públicas y privadas del país; lo cual lo convierte per se en una región de atracción, como se indicó anteriormente.

Además, se debe destacar que sí bien hay presencia de procesos migratorios en todos los grupos de edades, también se muestra grupos etarios que presentan una clara expulsión, principalmente en las regiones de tipo rural, y transfronterizas, en las que en los grupos quinquenales dentro del rango de persona joven, se observa una disminución en tales grupos poblacionales en dichas regiones. 


\section{La migración interna en Costa Rica y las dinámicas de desarrollo con el TLC}

La migración interna en Costa Rica ha sido un tema de escaso interés desde el punto de vista de los estudios migratorios, en tanto la migración internacional ha acaparado la atención desde la década de los 80 , cuando tomó auge este fenómeno dado el contexto político y económico de Centroamérica, como señala Molina 2009, al citar a Barquero, citado a su vez por CELADE 2008.

En Costa Rica, en los últimos veinte años prácticamente no se ha producido investigación en materia de migración interna, debido en parte al tiempo que transcurrió sin realizarse el Censo Nacional de Población entre 1984 y 2000, lo que privó de datos a los investigadores especializados, y de otra parte debido al estudio prioritario de la inmigración internacional principalmente de nicaragüenses, a partir de la década de los noventa (Molina 2008, 2$3)$.

Sin embargo, eso se convierte en un incentivo desde plano investigativo para la realización de estudios contemporáneos sobre la migración interna en el país, principalmente desde un eje del desarrollo económico que pareciera continuar asociado a la causa primordial de las migraciones internas: el empleo.

Por lo que a pesar de que hay claridad de que el país maneja límites referentes a provincia, cantón y distrito; se debe considerar la existencia de la división geográfica por regiones socioeconómicas que desde el punto de vista de las dinámicas de desarrollo asociadas a la generación de empleo; lo cual permite considerar un análisis más sensato de la situación actual, Por lo anterior, se considera una recomendación a tomar en cuenta que para el análisis de la migración interna desde este enfoque de desarrollo, es elemental el abordaje desde las regiones socioeconómicas del país.

Se reconoce cómo Costa Rica en materia de desarrollo ha pasado por un proceso de transformación de las dinámicas de empleo en las últimas décadas, convirtiéndose de un país de gran actividad vinculada a producción agrícola a la diversificación del empleo, en la que ha crecido el sector terciario dedicado a servicios.

Tal como lo plantea Roldan (2012), dichas transformaciones de los mercados laborales van generando impactos paulatinos en los flujos migratorios; de forma tal que a su vez se generan impactos a nivel social y económico en los 
hogares con componente migratorio; pero esta distinción de regiones con mayor expulsión y de mayor atracción en el país. Como se mencionó anteriormente en los resultados obtenidos, podría vincularse directamente a la forma en la cual se genera el desarrollo económico en el país.

Por ejemplo, para el 2008; primer año de vigencia del TLC; fueron notorias éstas diferencias por región socioeconómica en el país; como lo señala el Estado de la Nación: "a pesar de que Costa Rica es un país pequeño y con políticas públicas de alcance nacional, cuando se analiza por regiones geográficas los resultados en indicadores clave del desarrollo humano, se observan grandes diferencias" (2011, p. 49).

Figura 5. Indicadores por región socioeconómica de Costa Rica, 2008

Costa Rica: indicadores seleccionados por región. 2008

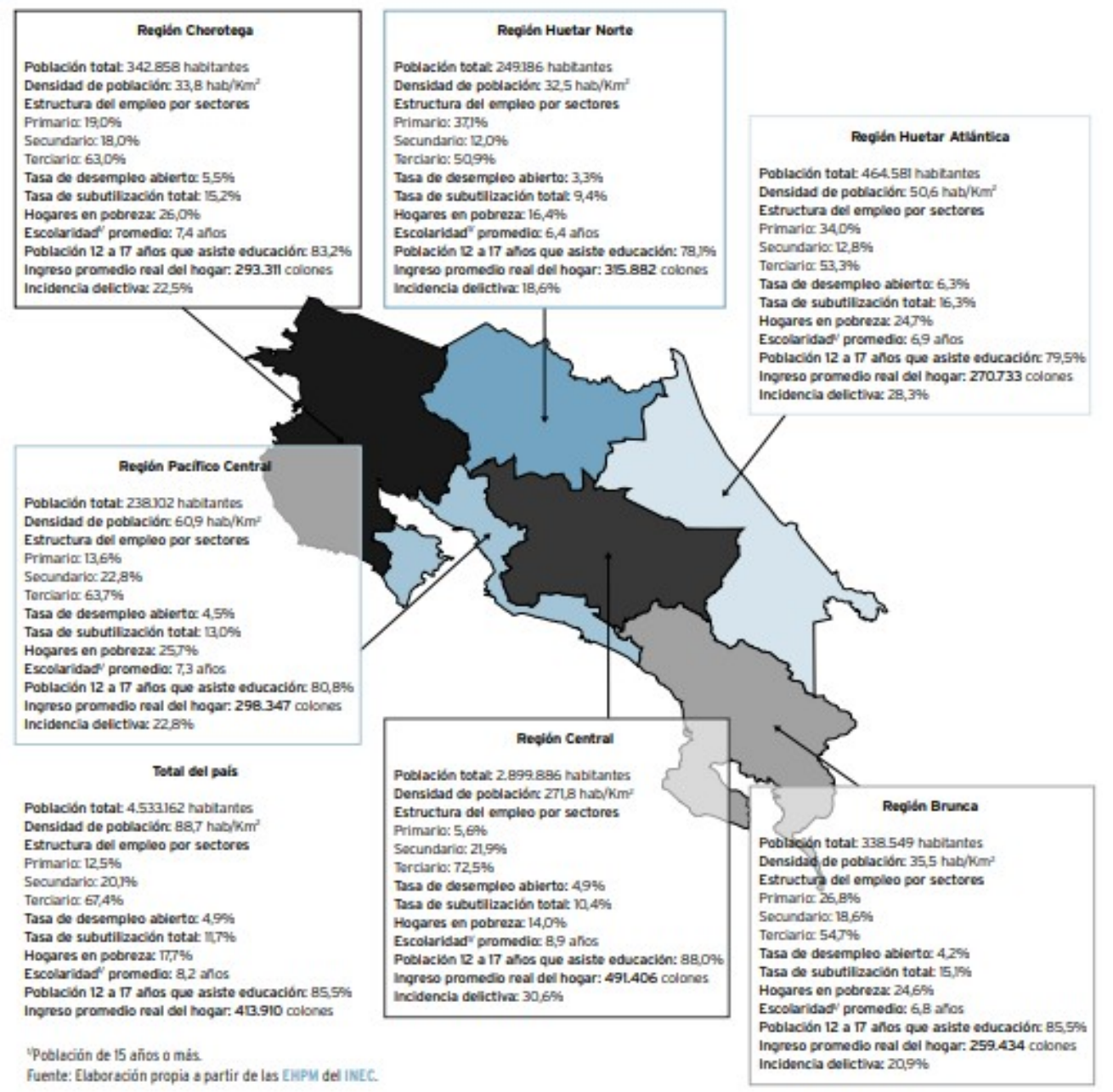

Decimoquinto Informe Estado de la Nación, 2009. 
Lo anterior, en tanto desde el punto de vista teórico de Wallerstein (1974), a partir de la visión sistema-mundo; el centro y la periferia no se limitan al plano de la división geográfica de los países; sino que son tangibles dentro de los sublímites como región, provincia o cantón.

Los factores que parecen influir en este aumento de la pobreza en las regiones periféricas tienen que ver con la dinámica del mercado de trabajo, pues como se ha visto, estas regiones (con excepción de la Huetar Norte) son muy afectadas por niveles mayores de desempleo y subempleo, e inserción en sectores de baja productividad, así como en los sectores informal y agropecuario (Decimoquinto Informe Estado de la Nación, 2009, p. 51).

Vinculado a las dinámicas de empleo, de la misma forma las migraciones se han asociado a las implicaciones que éstas tienen para el crecimiento económico; así lo apuntan Gómez y Madrigal (2004) al analizar el comportamiento histórico de la migración interna en el país desde 1927 hasta el año 2000, la migración neta ha obedecido a factores específicos como:

1) La construcción de los ferrocarriles al Atlántico y al Pacífico, y de carreteras que comunicaron el Valle Central con la Zona Norte, Guanacaste, Zona Sur y la Región Atlántica, que facilitaron la colonización de la frontera agrícola.

2) El desarrollo y evolución de la actividad económica -especialmente agrícola- en las diferentes zonas del país, como sucedió con el cultivo del banano, inicialmente en la región Atlántica, luego en el Pacífico y, más recientemente, de nuevo en el Atlántico.

3) La dinámica del proceso de desarrollo de una economía moderna, que ha estimulado el movimiento rural-urbano y el crecimiento de la Región Metropolitana de San José, y de los centros urbanos que la rodean, como Heredia, Cartago y Alajuela.

En la historia reciente del país, el hecho de la aprobación del TLC podría haber marcado un nuevo momento de asociación con la migración interna; sin embargo, los resultados expuestos anteriormente reflejan que no ha habido cambios significativos que hagan considerar variaciones; por el contrario, persisten los flujos migratorios que regularmente se han venido asociando a las dinámicas de desarrollo de la economía moderna.

De acuerdo con los resultados de la Encuesta Nacional de Hogares (ENAHO) del INEC (2017), la pobreza está presente en todas las regiones socioeconómicas del país; sin embargo es notorio que para regiones como la 
Huetar Norte, la Huetar Caribe, la Brunca y la Pacífico Central, su incidencia es mayor con respecto a la Central y la Chorotega; con lo cual se marca con más fuerza los efectos de esta diferenciación de las dinámicas de desarrollo por región socioeconómica.

Figura 6 Incidencia de la pobreza por región socioeconómica, 2017

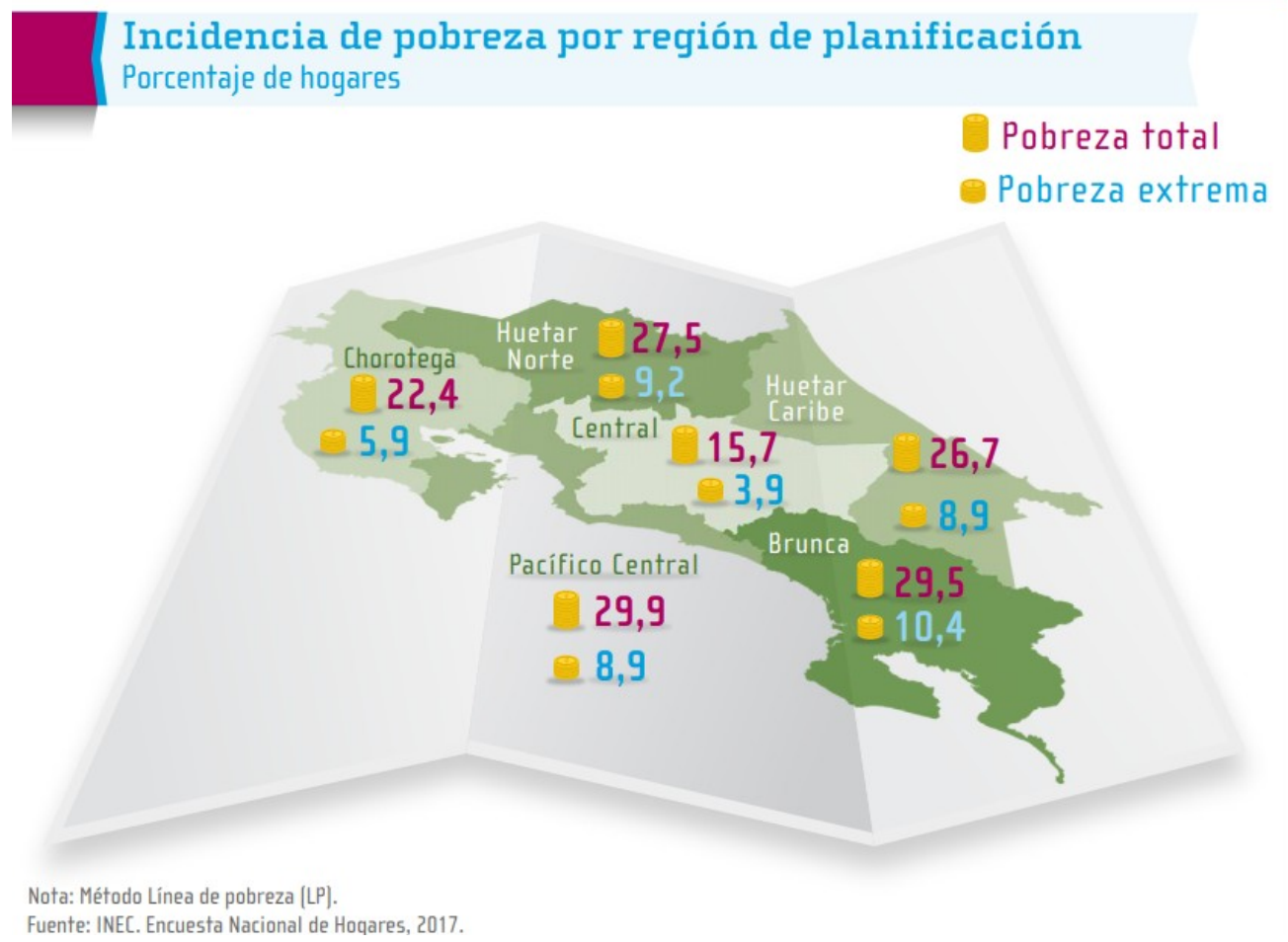

Por otra parte a nivel de todo el país, el empleo persistente como la principal fuente de ingreso de los hogares, como lo señaló el 79,9\%; es necesario destacar que de ese porcentaje, 62,8\% corresponde a ingreso por salario, mientras que el restante $17,1 \%$ se asocia a ingreso por trabajo autónomo; por tanto, permanece una clara dependencia del empleo asalariado, a la que no se debe restar importancia, en el tanto la promesa de más y mejores empleos con el TLC, así como el desarrollo de nuevos emprendedurismos que aún no se cumple.

\section{Consideraciones finales}

Acorde a lo anterior, debe resaltarse la importancia de identificar las etapas migratorias planteadas en el indicador, que está viviendo la población costarricense; en función de los procesos migratorios, pero además de procesos 
de desarrollo económico, en los cuales se distinguen premisas importantes como:

- La necesidad de observar desde el punto de vista histórico, el reflejo de los acontecimientos político-económicos contemporáneos como el llamado TLC, en la lectura de las migraciones de la población costarricense.

- La presencia de una creciente feminización de los flujos migratorios al observar en la población migrante un índice de masculinidad menor en algunas de las regiones socioeconómicas del país.

- Persiste el flujo migratorio desde las regiones de menor desarrollo hacia las regiones de mayor desarrollo; sin embargo, se denota a su vez la presencia de flujo migratorio de expulsión desde el la Región Metropolitana, que podría asociarse incluso al acceso a vivienda, más que a las condiciones de empleo.

- El empleo continúa como uno de los principales motivos de migración interna, razón por la cual algunas de las regiones del país fungen como espacios geográficos de atracción o expulsión de población, sin embargo las tendencias de estas etapas migratorias no variaron de forma significativa del periodo censal 2000 y el periodo censal 2011; a pesar de las expectativas frente a la aprobación del TLC, que prometían cambios en las opciones y cantidad de empleo disponibles para todo el país.

\section{Bibliografía}

Brenes Solano Vera. 2011. "Las regiones socioeconómicas de Costa Rica. Una posibilidad de abordaje". https://estadonacion.or.cr/files/biblioteca_virtual/educacion/propuestaregiones-primaria-para-web.pdf

Fallas Helio. 2012. "A cuatro años del TLC de Costa Rica con Estados Unidos de Norteamérica". Tribuna Democrática. http://www.tribunademocratica.com/2012/05/a-cuatro-anos-del-tlc-decosta-rica-con-estados-unidos-de-norteamerica/

Gómez Barrantes, Miguel; Madrigal Pana, Johnny. 2004. “Migración Interna en Costa Rica en el período 1927-2000". http://biblioteca.ccp.ucr.ac.cr/handle/123456789/1192

González, Daniela. 2011. MIGRACIÓN INTERNA Taller Regional sobre "Potencialidades y aplicaciones de los datos censales", CELADEDivisión de Población de la CEPAL 12 al 14 de octubre de 2011. http://www.cepal.org/celade/noticias/paginas/5/45125/DGonzalez.pdf 
INEC 2017. Infografía ENAHO 2017, ENCUESTA NACIONAL DE HOGARES 2017.

http://www.inec.go.cr/sites/default/files/infografias-pdf/imgenaho_2017.p df

INEC. 2000. "Cuestionario censal 2000 Costa Rica". http://www.inec.go.cr/metodologias/cuestionarios

INEC. 2001. "Base de datos Censo Nacional de Población 2000 Costa Rica"

INEC. 2012. "Base de datos Censo Nacional de Población 2011 Costa Rica"

Jasper, Dirk. 2006. "Manual sobre indicadores de calidad de vida en la vejez".

CELADE-CEPAL. http://www.observatorionacionaldoidoso.fiocruz.br/biblioteca/_manual/ 17.pdf

León, Amparo Micolta. 2005. "Teorías y conceptos asociados al estudio de las migraciones internacionales". Trabajo Social, Revista del Departamento de Trabajo Social, Facultad de Ciencias Humanas, Universidad Nacional de Colombia https://revistas.unal.edu.co/index.php/tsocial/article/view/8476

Martínez Martín, A F. 2011. "Reflexiones en torno al sistema mundo de Immanuel Wallerstein". Revista Historia Y MEMORIA, 2() 211-220. Recuperado de http://www.redalyc.org/articulo.oa?id=325127478010

Movimiento No. 2007. "Esto es lo que no quieren que usted lea sobre el TLC Argumentos del No", recuperado de http://www.tlc.estadonacion.or.cr/documentos/pdfs/55MovimientoNO200 7.pdf

Programa Estado de la Nación en Desarrollo Humano Sostenible. 2005. "Aportes para el análisis del Tratado de Libre Comercio Centroamérica, República Dominicana y Estados Unidos". Programa Estado de la Nación, San José C.R. http://www.estadonacion.or.cr/files/biblioteca_virtual/otras_publicacione s/aporte9 tlc.pdf

Programa Estado de la Nación. 2009. "Decimoquinto Informe Estado de la Nación en Desarrollo Humano Sostenible". San José, Programa Estado de la Nación. https://www.estadonacion.or.cr/index-en/informe-xvestado-nacion

Roldan Dávila, Genoveva. 2012. "Una aportación ignorada de la teoría neoclásica al estudio de la migración laboral". Migración y desarrollo [online]. 2012, vol.10, n.19 [citado 2017-09-03], pp. 61-91. <http://www.scielo.org.mx/scielo.php?script=sci_arttext\&pid=S187075992012000200003\&lng=es\&nrm=iso>. ISSN 1870-7599.

Tapinos, George. 1990. "Elementos de demografía”, Madrid, Espasa-Calpe, 410 p. (Título original: Eléments de Démographie, Armand Colin, Paris, 1985). 
Vargas Solís, Luis Paulino. 2007. "TLC, empleo e inversión extranjera: La historia NO oficial. Asociación Nacional de Empleados Públicos y Privados". https://www.anep.or.cr/article/tlc-empleo-e-inversionextranjera-la-historia-no-ol 